\title{
PENGGUNAAN MEDIA MASSA DAN INTERNET SEBAGAI SARANA PENYAMPAIAN INFORMASI DAN PROMOSI OLEH PENGELOLA INDUSTRI KECIL DAN MENENGAH DI BANDUNG
}

\author{
Gumgum Gumilar, Ipit Zulfan \\ Fakultas Ilmu Komunikasi, Universitas Padjadjaran
}

\begin{abstract}
ABSTRAK
Penelitian ini bertujuan untuk mengetahui bagaimana media massa dan Internet dipergunakan sebagai sarana penyebarluasan informasi dan promosi oleh pengelola industri kecil dan menengah di kota Bandung. Penelitian ini menggunakan pendekatan dan metode penelitian kuantitatif, yaitu survei dengan teknik analisis deskriptif. Data yang diperoleh dengan menyebarkan kuesioner, wawancara, studi pustaka dan pencarian data di Internet. Sampel diperoleh dengan teknik proporsional random sampling dimana diperoleh ukuran sampel 96. Hasil penelitian memperlihatkan bahwa hanya sebagian kecil pengelola industri kecil dan menengah menggunakan media massa dan Internet. Intensitas penggunaan media massa dan Internet sangat tergantung pada media yang digunakan. Media yang paling sering digunakan oleh pengelola industri kecil dan menengah adalah email. Informasi yang paling dominan disampaikan di media massa dan Internet adalah informasi mengenai produk. Tidak ada cara khusus yang dilakukan oleh pengelola industri kecil dan menengah untuk menentukan media mana yang digunakan untuk menyebarkan informasi dan promosi, mereka lebih banyak bergantung pada promosi dari mulut ke mulut dari konsumen yang pernah menggunakan produknya. Berkaitan dengan biaya, Internet menjadi media alternatif untuk sarana promosi karena biayanya relatif murah dibandingkan dengan media lainnya. Kesimpulannya, pemahaman pengelola usaha kecil dan menengah terhadap fungsi media massa dan Internet untuk menyebarkan informasi dan promosi masih kurang, padahal banyak media, terutama Internet, tidak memerlukan biaya besar dalam penggunaannya.
\end{abstract}

Kata-kata Kunci: Media massa, Internet, informasi, promosi, usaha kecil menengah

\section{THE USE OF MASS MEDIA AND THE INTERNET AS A TOOL FOR SUBMISSION OF INFORMATION MANAGEMENT AND PROMOTION BY SMALL AND MEDIUM ENTERPRISES IN BANDUNG}

\begin{abstract}
This study aims to determine how the mass media and the Internet are used as a medium of dissemination on information and promotion of small and medium business in Bandung. This study uses a quantitative approach and used research method of survey with a descriptive analysis techniques. Data obtained by distributing questionnaires, interviews, literature study and data searching in Internet. Samples were obtained by proportional random sampling technique where the sample size obtained are 96. The results shows that only a fraction of small and medium-sized industrial managers using the mass media and the Internet. The intensity of mass media and the Internet use is depend on which media being used. The media most frequently used by managers of small and medium industries is email. The most dominant of information conveyed in the mass media and the Internet is the information about the product. There is no special way by the management of small and medium industries to determine which media are being used to disseminate information and promotion, which rely on word of mouth promotion from their consumers who have used the products. In expenses respect, the Internet becomes an alternative medium for promotion as they are relatively cheap compared to other media. In conclusion, the understanding of small and medium business managers to the functions of the mass media and the Internet to disseminate information and promotion is not sufficient, although many media, especially the Internet does not require a large fee for its use.
\end{abstract}

Keywords: Mass media, Internet, information, promotion, small and medium businesses

Korespondensi: Gumgum Gumilar, S.Sos., M.Si Fakultas Ilmu Komunikasi Universitas Padjadjaran, Jl. Raya Bandung-Sumedang KM. 21 Sumedang.Email: re_gumilar@yahoo.com 


\section{PENDAHULUAN}

Menurut Biagi (2010), istilah Industri media massa (mass media industries) menggambarkan delapan jenis usaha atau bisnis media massa. Kedelapan industri media tersebut adalah: (1) Buku, (2) Surat Kabar, (3) Majalah, (4) Rekaman, (5) Radio, (6) Film, (7) Televisi, dan (8) Internet.

Fungsi media massa pada hakikatnya sejalan dengan fungsi komunikasi massa karena media massa adalah bagian dari komunikasi massa. Fungsi komunikasi massa secara umum adalah fungsi informasi, fungsi pendidikan dan fungsi mempengaruhi (Effendy, 2005). Secara khusus DeVito (1996) menyebutkan salah satu fungsi komunikasi massa adalah fungsi untuk meyankinkan (to persuade), fungsi tersebut bisa datang dalam bentuk; (a) Mengukuhkan atau memperkuat sikap, kepercayaan, atau nilai seseorang, (b) Mengubah sikap, kepercayaan, atau nilai seseorang, (c) Menggerakkan seseorang untuk melakukan sesuatu, dan (d) Memperkenalkan etika atau menawarkan sistem nilai tertentu.

Dua fungsi utama dalam melakukan komunikasi melalui media massa tersebut banyak digunakan oleh sektor industri, terutama untuk menyebarkan informasi dan melakukan promosi mengenai industri mereka. Diantaranya adalah penggunaan media massa oleh sektor industri kecil dan menengah di Kota Bandung.

Menurut Hani Nurrosjani, Kepala Bidang Industri Disperindag Kota Bandung, saat menyampaikan makalahnya dalam seminar Pengembangan 7 kawasan Kota Bandung, terdapat tujuh kawasan industri yang berpotensi menjadi pusat bisnis, yaitu Sentra Sepatu Cibaduyut, Sentra Pakaian Jins Cihampelas, Sentra Kaos dan Sablon Suci, Sentra Rajut Binong Jati, Sentra Tekstil dan Produk Tekstil Cigondewah, Sentra Tahu dan Tempe Cibuntu, dan Sentra Boneka Sukamulya.

Awal dekade 1990-an teknologi Internet masih terbilang asing untuk sebagian besar masyarakat Indonesia. Saat itu, Internet hanya dapat diakses oleh segelintir orang karena untuk mengakses Internet dibutuhkan biaya yang tidak sedikit ditambah minimnya jumlah pengguna personal computer atau $p c$. Sejalan bergulirnya waktu, aksesibilitas teknologi Internet menjadi semakin luas dan mudah. Menurut data yang dilansir Asosiasi Penyelenggara Jasa Internet Indonesia (APJII), sampai awal tahun 2009 tercatat sekitar 25 juta pengguna Internet. Kedepannya angka ini akan meningkat tajam karena APJII menghitung bahwa pengguna Internet meningkat 25 persen per tahun.

Sekarang teknologi informasi berkembang semakin cepat. Hampir sebagian besar dari kegiatan manusia memanfaatkan kecanggihan teknologi informasi. Perkembangan teknologi informasi memunculkan berbagai jenis kegiatan yang berbasis pada teknologi informasi, seperti e-government, e-commerce, e-education dan lainnya.

Penggunaan media massa oleh setiap sentra industri tentulah tidak sama, hal ini terkait banyak hal diantaranya kemampuan mereka untuk mempergunakan media tersebut. Pengelola sentra industri bisa jadi menggunakan semua jenis media massa, tetapi kemungkinan ada sentra industri yang hanya menggunakan satu jenis media saja.

Pemetaan penggunaan media massa oleh pengelola sentra industri dapat menjadi dasar untuk melakukan penelitian atau kegiatan pengabdian masyarakat selanjutnya. Selain itu penelitian ini menyangkut isu strategis teknologi komunikasi dan globalisasi informasi khususnya studi kebijakan tentang penggunaan teknologi komunikasi mutakhir yang mempertimbangkan kearifan lokal, karena industri kecil dan menengah di Kota Bandung sebagian besar bergerak dari kearifan lokal.

\section{METODE PENELITIAN}

Penelitian ini merupakan penelitian kuantitatif dengan menggunakan metode survei dan teknik analisis data deskriptif. Metode penelitian kuantitatif dapat diartikan sebagai metode penelitian yang berlandaskan pada filsafat positivisme, digunakan untuk meneliti pada populasi dan sampel tertentu, pengumpulan data dan menggunakan instrumen penelitian, analisis data bersifat kuantitatif/statistik, dengan tujuan untuk menguji hipotesis yang telah ditetapkan (Sugiyono, 2009: 8)

Metode survei merupakan metode riset dengan menggunakan kuesioner sebagai instrumen pengumpulan datanya. Tujuannya untuk memperoleh informasi tentang sejumlah responden yang dianggap mewakili populasi ter- 
tentu. Dalam survei proses pengumpulan dan analisis data sosial bersifat sangat tersetruktur dan mendetail melalui kuesioner sebagai instrumen utama untuk mendapatkan informasi dari sejumlah responden yang diasumsikan mewakili populasi yang spesifik (Rakhmat, 2009: 59). Teknik analisis data deskriptif bertujuan untuk mencari dan mendeskripsikan fenomena yang terjadi masyarakat tanpa bermaksud mencari hubungan antara variabel satu dengan variabel lain (Sugiyono, 2009: 35).

\section{HASIL DAN PEMBAHASAN}

Berdasarkan hasil penelitian, diperoleh data Responden penelitian berjumlah 96 orang, berikut adalah tabel sebaran responden berdasarkan sentra industri.

Tabel 9. 1 Usia Responden

\begin{tabular}{ccc}
\hline UMUR & F & \% \\
\hline $18-28$ & 32 & 33,33 \\
\hline $29-38$ & 27 & 28,18 \\
\hline $39-48$ & 21 & 21,88 \\
\hline $49-58$ & 16 & 16,67 \\
\hline Jumlah & $\mathbf{9 6}$ & $\mathbf{1 0 0}$
\end{tabular}

Sumber: Hasil Penelitian 2012

Berdasarkan data pada Tabel 1, dapat dilihat usia responden yang merupakan pengelola industri kecil dan menengah paling banyak berkisar antara 18 - 28 tahun sebanyak 33,33 $\%$, bahkan lebih dari $60 \%$ berusia di bawah 40 tahun.
Tabel 9. 2 Jenis Kelamin

\begin{tabular}{ccc}
\hline $\begin{array}{c}\text { JENIS } \\
\text { KELAMIN }\end{array}$ & $\mathrm{F}$ & $\%$ \\
\hline Laki-laki & 80 & 83,33 \\
\hline Perempuan & 16 & 16,67 \\
\hline Jumlah & 96 & 100 \\
\hline
\end{tabular}

Sumber: Hasil Penelitian 2012

Berdasarkan Tabel 2 dapat dilihat responden terbanyak berjenis kelamin laki-laki yakni berjumlah 80 orang atau sekitar 83,33\%. Pada Tabel 3 dijelaskan jenis usaha dari respon yang terbanyak adalah dari industri sepatu berjumlah 23 orang, ini dikarenakan industri sepatu merupakan sentra industri dengan jumlah usaha terbesar yang terletak di Cibaduyut, sedangkan yang terkecil adalah pengelola boneka dengan jumlah responden 1 orang.

Tabel 9. 3 Jenis Usaha

\begin{tabular}{ccc}
\hline UMUR & $\mathrm{F}$ & $\%$ \\
\hline $\begin{array}{c}\text { Konpeksi dan } \\
\text { Sablon }\end{array}$ & 17 & 17,71 \\
\hline Rajut & 13 & 13,54 \\
\hline Jeans & 3 & 3,13 \\
\hline Sepatu & 23 & 23,96 \\
\hline Tekstil & 13 & 13,54 \\
\hline Tahu/Tempe & 18 & 18,75 \\
\hline Pakaian Anak & 4 & 4,17 \\
\hline Percetakan & 2 & 2,08 \\
\hline Boneka & 1 & 1,04 \\
\hline Perajin Tas & 2 & 2,08 \\
\hline Jumlah & 96 & 100 \\
\hline Sumber:Hasil Penclitan
\end{tabular}

Sumber: Hasil Penelitian 2012

Tabel 9. 4 Penggunaan Media Massa Oleh Pengelola Sentra Industri Kecil di Bandung

\begin{tabular}{ccccccccc}
\hline \multirow{2}{*}{$\begin{array}{c}\text { Menggunakan } \\
\text { Media }\end{array}$} & Surat Kabar & \multicolumn{2}{c}{ Majalah } & \multicolumn{2}{c}{ Radio } & \multicolumn{2}{c}{ Televisi } \\
\cline { 2 - 9 } & $\mathrm{F}$ & $\%$ & $\mathrm{~F}$ & $\%$ & $\mathrm{~F}$ & $\%$ & $\mathrm{~F}$ & $\%$ \\
\hline Ya & 11 & 11,5 & 8 & 8,3 & 4 & 4,2 & 6 & 6,25 \\
\hline Tidak & 85 & 88,5 & 88 & 91,7 & 92 & 95,8 & 90 & 93,75 \\
\hline Jumlah & 96 & 100 & 96 & 100 & 96 & 100 & 96 & 100 \\
\hline
\end{tabular}

Sumber: Data Hasil Penelitian 2012 
Tabel 9. 5 Frekuensi Penggunaan Media Massa Untuk Promosi

\begin{tabular}{ccccccccc}
\hline \multirow{2}{*}{$\begin{array}{c}\text { Frekuensi } \\
\text { Penggunaan }\end{array}$} & \multicolumn{2}{c}{ Surat Kabar } & \multicolumn{2}{c}{ Majalah } & \multicolumn{2}{c}{ Radio } & \multicolumn{2}{c}{ Televisi } \\
\cline { 2 - 9 } & $\mathrm{F}$ & $\%$ & $\mathrm{~F}$ & $\%$ & $\mathrm{~F}$ & $\%$ & $\mathrm{~F}$ & $\%$ \\
\hline Setiap hari & 1 & 9,1 & 0 & 0 & 1 & 25 & 0 & 0 \\
\hline Seminggu sekali & 2 & 18,2 & 1 & 12,5 & 0 & 0 & 1 & 16,7 \\
\hline Sebulan sekali & 1 & 9,1 & 2 & 25 & 1 & 25 & 1 & 16,7 \\
\hline Tidak tetap & 7 & 63,7 & 5 & 62,5 & 2 & 50 & 4 & 66,6 \\
\hline Jumlah & 11 & 100 & 8 & 100 & 4 & 100 & 6 & 100 \\
\hline
\end{tabular}

Sumber: Data Hasil Penelitian 2012

Data selanjutnya yang digali dalam penelitian ini adalah penggunaan media massa oleh usaha kecil menengah di Kota Bandung dalam mempromosikan usahanya, di Tabel 4 pada halaman sebelumnya. Penelitian ini difokuskan pada penggunaan media massa cetak dan elektronik, yaitu surat kabar, majalah, radio dan televisi. Berikut ini akan diuraikan hasil penelitian penggunaan media massa tersebut.

Hasil penelitian yang dilakukan memperlihatkan, penggunaan media massa oleh pengelola industri kecil dan menengah di Kota Bandung masih sangat rendah, berkisar antara 4,2 s.d. 11,5 persen.

Surat kabar menempat urutan tertinggi dengan persentase penggunaan sebesar 11,5 persen sedangkan radio terendah dengan angka 4,2 persen. Banyak hal yang menyebabkan rendahnya penggunaan media massa ini, antara lain tidak adanya dana khusus untuk promosi, media yang datang untuk meliput sentra industri mereka dan berharap promosi dari mulut ke mulut yang dilakukan oleh konsumen mereka.

Berdasarkan jumlah pengguna yang di- paparkan pada Tabel 5, didapatkan frekuensi penggunaan media massa berdasarkan jenis media yang mereka gunakan. Angka penggunaan tertinggi untuk penggunaan ada pada frekuensi penggunaan yang tidak tetap, ini memperlihatkan kecenderungan mereka untuk mempergunakan media apabila diperlukan saja, tidak memiliki pengaturan waktu kapan mereka mempergunakan media massa.

Hasil penelitian di Tabel 6 memperlihatkan, sebagian besar responden mempergunakan media massa untuk mempromosikan produk mereka dan juga peluncuran produk baru. Angka terkecil ada pada informasi mengenai perusahaan, ini dikarenakan saat mempromosikan produk, otomatis nama perusahaan pun akan diikutsertakan, jadi tidak perlu promosi khusus.

Penggunaan media cetak yang disurvei adalah penggunaan surat kabar dan majalah. Survei yang dilakukan terhadap 96 responden tersebut menghasilkan data sebagai berikut yang dapat dilihat pada Tabel 7 di halaman berikut:

Tabel 9. 6 Informasi Yang Disampaikan Melalui Media Massa

\begin{tabular}{ccccccccc}
\hline \multirow{2}{*}{ Frekuensi Penggunaan } & \multicolumn{2}{c}{ Surat Kabar } & \multicolumn{2}{c}{ Majalah } & \multicolumn{2}{c}{ Radio } & \multicolumn{2}{c}{ Televisi } \\
\cline { 2 - 9 } & $\mathrm{F}$ & $\%$ & $\mathrm{~F}$ & $\%$ & $\mathrm{~F}$ & $\%$ & $\mathrm{~F}$ & $\%$ \\
\hline Promosi produk & 1 & 9,1 & 4 & 50 & 2 & 50 & 4 & 50 \\
\hline Peluncuran produk baru & 2 & 18,2 & 4 & 50 & 2 & 50 & 2 & 25 \\
\hline Informasi perusahaan & 1 & 9,1 & 0 & 0 & 0 & 0 & 1 & 12,5 \\
\hline Kegiatan sosial & 7 & 63,7 & 0 & 0 & 0 & 0 & 1 & 12,5 \\
\hline Jumlah & 11 & 100 & 8 & 100 & 4 & 100 & 8 & 100 \\
\hline
\end{tabular}

Sumber: Data Hasil Penelitian 2012 
Tabel 9. 7 Surat Kabar yang Digunakan

\begin{tabular}{lll}
\hline Surat Kabar & F & $\%$ \\
\hline PR & 4 & 36,4 \\
\hline Kompas & 1 & 18,2 \\
\hline Bisnis Indonesia & 1 & 9,1 \\
\hline Koran tempo & 1 & 9,1 \\
\hline Galamedia & 0 & 0 \\
\hline Radar Bandung & 1 & 9,1 \\
\hline Tribun Jabar & 3 & 27,1 \\
\hline Jumlah & 11 & 100 \\
\hline Sumber: Data Hasil Penclian 2012
\end{tabular}

Sumber: Data Hasil Penelitian 2012

Pikiran rakyat merupakan surat kabar yang paling banyak digunakan oleh pengelola ukm untuk mempromosikan usahanya. Dari 11 orang responden, empat diantaranya menggunakan pikiran rakyat.

Berdasarkan Tabel 7 di atas dapat dilihat, tujuh responden menggunakan surat kabar regional untuk menyebarkan informasinya, yaitu Pikiran Rakyat dan Tribun Jabar. Tiga responden menggunakan surat kabar nasional (KOMPAS, Bisnis Indonesia dan Koran Tempo) sedangkan yang menggunakan surat kabar lokal (Radar Bandung) satu responden.

Tabel 9.8 Majalah yang Digunakan

\begin{tabular}{llc}
\hline \multicolumn{1}{c}{ Majalah } & F & $\mathbf{\%}$ \\
\hline Tempo & 1 & 12,5 \\
\hline Warta Ekonomi & 1 & 25 \\
\hline UKM Indonesia & 2 & 12,5 \\
\hline Lainnya & 4 & 50 \\
\hline Jumlah & $\mathbf{8}$ & $\mathbf{1 0 0}$ \\
\hline
\end{tabular}

Sumber: Data Hasil Penelitian 2012

Berkenaan dengan penggunaan majalah, setengah dari responden yang menggunakan majalah ternyata memilih majalah selain yang ditampilkan dalam pilihan. Majalah yang digunakan lebih ke majalah lokal atau majalah promosi pariwisata yang pemuatannya tidak menggunakan biaya yang besar. Atau memang manjadi bahan liputan untuk dijadikan laporan dalam majalah tersebut.

Dua responden menggunakan majalah UKM Indonesia, dan dua orang lagi terbagi menggunakan majalah tempo dan warta ekonomi. Seperti disampaikan pada bagian sebelumnya, majalah segmentasi khalayaknya lebih terbatas sehingga promosi yang dilakukanpun terbatas.

Tabel 9.9 Radio yang Dipergunakan untuk Promosi

\begin{tabular}{ccc}
\hline Radio & F & $\%$ \\
\hline PR FM & 1 & 20 \\
\hline OZ & 0 & 0 \\
\hline ARDAN & 0 & 0 \\
\hline DAHLIA & 0 & 0 \\
\hline RASE FM & 0 & 0 \\
\hline ANTASALAM & 2 & 40 \\
\hline GARUDA & 2 & 40 \\
\hline Jumlah & 5 & 100 \\
\hline
\end{tabular}

Sumber: Data Hasil Penelitian 2012

Hasil survei memperlihatkan, Radio Antassalam dan Radio Garuda menjadi radio yang paling banyak digunakan yaitu sebanyak masing-masing 2 responden atau $40 \%$. Responden ternyata tidak hanya menggunakan satu radio, dari hasil penelitian memperlihatkan ada satu responden yang menggunakan radio yang lain/ dua radio yaitu radio PRFM.

Tabel 9. 10 Stasiun Televisi yang Digunakan

\begin{tabular}{ccc}
\hline Televisi & F & $\%$ \\
\hline TVRI & 0 & 0 \\
\hline RCTI & 1 & 7,7 \\
\hline SCTV & 0 & 0 \\
\hline ANTC & 0 & 0 \\
\hline INDOSIAR & 0 & 0 \\
\hline TRANS TV & 4 & 30,8 \\
\hline TRANS 7 & 3 & 23,1 \\
\hline GLOBAL TV & 0 & 0 \\
\hline MNC TV & 0 & 0 \\
\hline TV ONE & 1 & 7,7 \\
\hline METRO & 1 & 7,7 \\
\hline STV & 0 & 0 \\
\hline BANDUNG TV & 2 & 15,4 \\
\hline PJTV & 1 & 7,7 \\
\hline IMTV & 0 & 0 \\
\hline Jumlah & 13 & 100 \\
\hline Sumber: Data Hasl Pencitan
\end{tabular}

Sumber: Data Hasil Penelitian 2012

Beberapa responden ternyata menggunakan televisi lebih dari satu stasiun televisi, ini terlihat dari hasil survei, berdasarkan enam 
Tabel 9. 11 Penggunaan Internet oleh Pengelola Sentra Industri Kecil Dan Menengah

\begin{tabular}{ccccccccccc}
\hline \multirow{2}{*}{$\begin{array}{c}\text { Menggunakan } \\
\text { Media }\end{array}$} & \multicolumn{2}{c}{ Email } & \multicolumn{2}{c}{ Forum } & \multicolumn{2}{c}{ Website/blog } & Facebook & \multicolumn{2}{c}{ Twitter } \\
\cline { 2 - 12 } & $\mathrm{F}$ & $\%$ & $\mathrm{~F}$ & $\%$ & $\mathrm{~F}$ & $\%$ & $\mathrm{~F}$ & $\%$ & $\mathrm{~F}$ & $\%$ \\
\hline Ya & 21 & 21,9 & 6 & 6,25 & 6 & 6,25 & 8 & 8,3 & 0 & 0 \\
\hline Tidak & 75 & 78,1 & 90 & 93,75 & 90 & 93,75 & 88 & 91,7 & 96 & 100 \\
\hline Jumlah & 96 & 100 & 96 & 100 & 96 & 100 & 96 & 100 & 96 & 100 \\
\hline
\end{tabular}

Sumber: Data Hasil Penelitian 2012

orang responden ternyata jumlah penggunaan televisinya 13 dengan terbanyak menggunakan TRANS TV. Jika dilihat dari tayangannya, TRANS TV merupakan salah satu media yang sering menampilkan keanekaragaman budaya termasuk didalamnya UKM yang fokus bisnisnya pada kekayaan budaya suatu daerah, atau menjadi cirri khas suatu daerah. Stasiun televisi selanjutnya yang banyak diguanakan adalah TRANS 7 yang kenyataannya merupakan stasiun televisi yang satu grup usaha dengan TRANS TV. Menariknya, ternyata televisi lokal pun menjadi pilihan responden yang itu Bandung TV dan PJTV.

Selain penggunaan media massa konvesional seperti telah diuraikan di atas, penggunaan Internet pun menjadi bagian dari survey ini. Perkembangan Internet sekarang ini berpengaruh terhadap berbagai bidang termasuk untuk menyebarkan informasi dan promosi.

Hasil penelitian memperlihatkan, penggunaan Internet untuk penyebaran informasi dan promosi oleh pengelola sentra industri kecil dan menengah sangatlah rendah. Angkat tertinggi pada penggunaan email yaitu sebesar 21,9 persen sedangkan angka terendah pada penggunaan twitter, dimana tidak satu orang responden pun menggunakan twitter.

Email yang memiliki angka tertinggi banyak digunakan oleh sentra industri sablon kaos suci, ini memperlihatkan fasilitas ini digunakan oleh jenis usaha yang berkaitan langsung, karena industri sablon sering menggunakan email untuk pengiriman desain dan contoh-contoh hasil produksi.

Sesuai dengan sifatnya yang cepat dan dapat diakses kapan saja, hasil penelitian memperlihatkan frekuensi penggunaan Internet paling tingi adalah setiap hari. Pengguna website/blog merupakan pengguna dengan frekuensi tertinggi yakni 66,66 persen sedangkan angka terendah pada frekuensi 3-4 kali dalam seminggu.

Tabel 9. 12 Frekuensi Penggunaan Internet Oleh Pengelola Sentra Industri Kecil dan Menengah

\begin{tabular}{ccccccccc}
\hline \multirow{2}{*}{$\begin{array}{c}\text { Menggunakan } \\
\text { Media }\end{array}$} & \multicolumn{2}{c}{ Email } & \multicolumn{2}{c}{ Forum } & Website/blog & \multicolumn{2}{c}{ Facebook } \\
\cline { 2 - 9 } & $\mathrm{F}$ & $\%$ & $\mathrm{~F}$ & $\%$ & $\mathrm{~F}$ & $\%$ & $\mathrm{~F}$ & $\%$ \\
\hline Setiap hari & 11 & 52,4 & 1 & 16,66 & 4 & 66,66 & 4 & 50 \\
\hline 5-6 kali seminggu & 7 & 33,3 & 0 & 0 & 0 & 0 & 2 & 25 \\
\hline 3-4 kali seminggu & 1 & 4,8 & 1 & 16,66 & 0 & 0 & 0 & 0 \\
\hline 1-2 kali seminggu & 0 & 0 & 1 & 16,66 & 1 & 16,66 & 0 & 0 \\
\hline Tidak tentu & 2 & 9,5 & 3 & 50 & 1 & 16,66 & 2 & 25 \\
\hline Jumlah & 21 & 100 & 6 & 100 & 6 & 100 & 8 & 100 \\
\hline
\end{tabular}

Sumber: Data Hasil Penelitian 2012 
Tabel 9. 13 Informasi yang Disampaikan Melalui Internet

\begin{tabular}{ccccccccc}
\hline \multirow{2}{*}{ Menggunakan Media } & \multicolumn{2}{c}{ Email } & \multicolumn{2}{c}{ Forum } & \multicolumn{2}{c}{ Website/blog } & \multicolumn{2}{c}{ Facebook } \\
\cline { 2 - 9 } & $\mathrm{F}$ & $\%$ & $\mathrm{~F}$ & $\%$ & $\mathrm{~F}$ & $\%$ & $\mathrm{~F}$ & $\%$ \\
\hline Promosi produk & 19 & 57,6 & 6 & 66,7 & 7 & 77,8 & 4 & 50 \\
\hline Peluncuran produk baru & 3 & 9,1 & 2 & 22,2 & 1 & 11,1 & 2 & 25 \\
\hline Informasi perusahaan & 9 & 27,2 & 0 & 0 & 0 & 0 & 2 & 25 \\
\hline Kegiatan social & 2 & 6,1 & 1 & 11,11 & 1 & 11,1 & 0 & 0 \\
\hline Jumlah & 33 & 100 & 9 & 100 & 9 & 11,1 & 8 & 100 \\
\hline
\end{tabular}

Sumber: Data Hasil Penelitian 2012

Seperti halnya media massa, informasi terbanyak yang disampaikan melalui Internet adalah promosi produk dengan angka berkisar antara 50 s.d. 77,8 persen, dengan angka tertinggi melalui website/blog.

\section{SIMPULAN}

Sebagian kecil pengelola sentra industri kecil dan menengah di Kota Bandung menggunakan media massa khususnya surat kabar, majalah, radio dan Internet. Mereka pun menggunakan Internet untuk menyebarkan informasi dan promosi, yaitu email, forum, website dan facebook, tidak satu pun pengelola industri kecil dan menengah menggunakan twitter untuk penyebaran informasi dan promosi.

Kecilnya penggunaan media massa dan Internet disebabkan sebagian besar tidak memiliki dana khusus untuk promosi, pengelolaan yang masih dilakukan secara tradisional dan pernah diliput media sehingga mereka merasa tidak perlu melakukan promosi lagi, tinggal menunggu konsumen datang.

Intensitas penggunaan media oleh pengelola industri kecil dan menengah beragam, tergantung jenis medianya. Namun, melihat karakteristik medianya maka dapat dilihat Internetlah yang paling sering diakses oleh pengelola media terutama email dan facebook yang sebagian besar penggunanya meng-update informasi setiap hari. Email merupakan media yang paling banyak digunakan oleh pengelola industri kecil dan menengah di Kota Bandung, terutama di sentra industri sablon kaos suci yang lebih banyak dikelola oleh anak muda.

Informasi yang disampaikan melalui media massa dan Internet sebagian besar mengenai produk yang dimiliki oleh industri kecil dan menengah, selanjutnya peluncuran produk baru dan kegiatan sosial. Sebagian kecil yang menggunakannya untuk menginformasikan perusahannya, hal ini disebabkan dengan menginformasikan produk otomatis nama perusahaan pun akan ikut terekspos.

Tidak ada cara khusus yang dilakukan oleh pengelola untuk menentukan media mana yang digunakan untuk menyebarkan informasi dan promosi, mereka lebih banyak tergantung pada promosi dari mulut ke mulut dari konsumen yang pernah menggunakan produknya. Berkaitan dengan dana, Internet menjadi alternatif media promosi karena biayanya relatif murah.

\section{DAFTAR PUSTAKA}

Ardianto, E., Komala, L., Karlinah, S. (2007). Komunikasi Massa Suatu Pengantar. Bandung: Simbiosa Rekatama Media.

Arikunto, Suharsimi.(2010). Prosedur Penelitian. Jakarta: Rineka Cipta

Biagi, S. (2010). Media/Impact Pengantar Media Massa. Jakarta: Salemba Humanika.

Dinas Koperasi UKM dan Perindustrian Perdagangan. 2012. 30 Sentra Industri Unggulan Kota Bandung.

Diakses dari www.sentraindustribandung.com.

Effendy, O. U. (2005). Ilmu Komunikasi, Teori dan Praktek. Bandung: Remaja Rosdakarya.

Fikri. (2009). 11 Manfaat Blog: Dari Media Aktualisasi hingga Mendapatkan penghasilan. Dari http://www.zimbio.com/member/ haryantoblog/articles/ 387-9805/ 5+Manfaat+Nyata + Membuat+Blog 
Littlejohn, S. W., Foss. Karen A. (2009). Teori Komunikasi - Theories of Human Communication. Jakarta: Salemba Humanika.

Kriyantono. (2009). Riset Komunikasi. Jakarta; Kencana Persada.

McQuail, D. (2011). Teori Komunikasi Massa, Buku 1 Edisi 6. Jakarta: Salemba Humanika. Mulyana, D. (2007). Ilmu Komunikasi Suatu Pengantar. Edisi revisi. Bandung: Remaja Rosdakarya.

Nugroho, Y., Putri, Dinita A,. Shita L. (2012). Mametakan Lansekap Industri Media Kon- temporer di Indonesia. Laporan Berseri Engaging Media, Empowering Society: Assessing media policy and governance in Indonesia through the lens of citizens' rights. Diunduh tanggal 9 Juli 2012 dari http:// mediarights.or.id/wp-content/uploads/downloads/2012/06/Pemetaan-Industri-Media_FINAL_v.6.pdf

Rakhmat, J. (2009). Metode Penelitian Komunikasi. Bandung: Remaja Rosdakarya.

Sugiyono. (2009). Metode Penelitian Kuantitatif, Kualitatif, dan $R \& D$. Bandung: Alfabeta. 